\title{
Application of AEC (RES) as a way to increase the competitiveness of industrial organizations
}

\author{
Alena $Y$. Tyutrina* \\ Novosibirsk State Technical University, Karl Marx Avenue, 20, 630073 Novosibirsk, Russia
}

\begin{abstract}
This article considers the necessity to replace traditional sources of electricity with renewable ones. An industrial enterprise is chosen as an object, on the basis of which the economic efficiency of installing microgrid as an active energy complex is calculated within the framework of the seventh goal of sustainable economic development.
\end{abstract}

\section{Introduction}

Within the framework of the concept of "Industry 4.0" or "Industrial revolution 4.0 ", the transition of industry to digital technologies, allows to develop new technical solutions for various production processes and technological chains, for example, to create new business models for large enterprises in various industries.

A striking example is the transition to digital solutions and control systems in the power supply of industrial enterprises, which provides new opportunities for deep integration of power equipment and software. As a result, at the present stage of industrial development, it becomes necessary to create new architecture of electric power systems that meets all the requirements of reliability and efficiency. One of these new types of power system architecture is an active energy complex, or AEC.

AEC are designed to provide enterprises in various sectors of economy with a tool for optimizing energy supply costs, ensuring the ability to achieve the goals of stable economic development adopted in 2015 by the UN. The agenda for Stable Development up to 2030 is a general plan for the long-term development of various sectors of economy to improve the quality of human life and protect the environment at the present and in the future [1]. It is based on 17 Stable Development Goals (SDGs), which are a roadmap for achieving the targets for both developed and developing countries in the global partnership.

The implementation and development of AEC has a number of goals, which are called 3D, namely, decarbonization of enterprises (reduction of carbon dioxide emissions), decentralization of energy resources and digitalization of enterprises (creating digital twins). All of them are targeted to developing energy efficient and resource-saving enterprise, which is reflected in the seventh goal of the SDG declaration - "Ensure access to affordable, reliable, stable and up-to-date energy for everyone". Therefore, the key point in the process of $3 \mathrm{D}$ program is the use of AEC.

The above makes it necessary to determine the degree of influence of the integration of AEC into the industrial complex in order to reduce the costs for production power supply

* Corresponding author: tyutrina@corp.nstu.ru 
and increase economic efficiency of the enterprise. During the research, it is necessary to find out how the use of AEC affects the competitiveness of industrial enterprises.

\section{AEC as a way to reduce energy costs}

Basically, the AEC is a micro-energy system consisting of its own generating facilities, its internal power grid infrastructure and its internal industrial consumer. They are all put together by a structure that includes digital solutions - a software and hardware complex of controlled intellectual connection (SHC CIC), with the help of which the regulation of production and consumption of electricity within the AEC is carried out, as well as technological interaction of the UES of Russia with the public grid. In the context of the ongoing project 2020-2023, "AEC is defined as a microgrid associated with the UES, which includes generation with a total capacity of up to $25 \mathrm{MW}$ that does not participate in the wholesale market, in which consumers are only industrial enterprises, administrative, business and shopping centers" [2].

The growth in the costs for enterprises power supply, as well as the development of distributed generation and digital technologies were prerequisites for the development and implementation of the AEC concept in the UES of Russia. Over the past few years, modern digital solutions have appeared which make it possible to manage industrial facilities effectively and balance the production and consumption of electricity. Preliminary studies show that for AEC consumers the cost for electricity will be at least $30 \%$ lower than the current one received from the external network [3]. For investors in the construction of thermal power plants, when implementing the AEC scheme, the efficiency of capital investment within eight years can reach up to $40 \%$ [4].

The annual volume of the world market for AEC or microgrids, according to calculations of Guidehouse Insights analytical company, is estimated at $\$ 8.1$ billion with the volume of new capacities commissioning at the level of $3.5 \mathrm{GW}$ per year. By 2028, this market will have grown up to $\$ 39.4$ billion per year with the annual commissioning of new capacities at the level of $19.9 \mathrm{GW}$. Now more than 6.6 thousand projects of microgrids are being implemented or have been planned all over the world [5].

In certain situations, microgrids can provide a reduction in costs for commercial and industrial consumers' power supply at the range of 5 to 25 or even more compared to energy consumption from the centralized energy system only. The magnitude of the effect depends both on the characteristics of specific consumers and on non-economic requirements, for example, in terms of reliability and environmental friendliness. Let us consider the experience of using microgrids at industrial enterprises in world practice [6].The more costly are network infrastructure reconstruction and construction activities necessary to eliminate the power shortage that consumers are experiencing or can experience in the nearest future, the higher the effect turns out to be.

Table 1. Calculation of the effect of using microgrids at industrial enterpises

\begin{tabular}{|c|c|c|}
\hline Enterprise & Configuration & Effects \\
\hline $\begin{array}{l}\text { Longmedow park } \\
\text { Location: Johannesburg, South } \\
\text { Africa } \\
\text { Commissioning year: } 2016 \\
\text { Integrator: ABB }\end{array}$ & $\begin{array}{l}\text { Power supply } \\
\text { Solar panels } \\
\text { Diesel generators }\end{array}$ & $\begin{array}{l}\text { Power supply costs reduction: } 25 \% \\
\mathrm{CO} 2 \text { (greenhouse gas) emission } \\
\text { reduction: } 1000 \text { tons per year } \\
\text { Increased reliability of power } \\
\text { supply }\end{array}$ \\
\hline $\begin{array}{l}\text { Esteblishment labs } \\
\text { Location: Costa Rica } \\
\text { Year of commissioning: } 2016 \\
\text { Integrator: ENEL }\end{array}$ & $\begin{array}{l}\text { Power supply } \\
\text { Solar panels }\end{array}$ & $\begin{array}{l}\text { Power supply costs reduction: } 5 \% \\
\text { Increased reliability of power } \\
\text { supply }\end{array}$ \\
\hline
\end{tabular}


The economic effect microgrids bring to consumers is formed by the following factors:

- reducing the costs for purchasing electricity and capacity on the market;

- $\quad$ reducing the costs for the transport of electricity paid to electric grids service;

- reducing the costs paid for technological connection or increasing the connected capacity;

- $\quad$ increasing the reliability of power supply and reducing losses from blackouts;

- improving the quality of electricity and reducing losses from the influence of voltage dips and surges on sensitive equipment.

In Russia, due to the peculiarities of price regulation in the electricity and capacity market, it is industrial consumers who are under the main pressure of the growing price for capacity, which includes an increasing share of fixed markups, as well as an increase in the costs for transmission services, which also contains a significant proportion of crosssubsidization. Since the costs for power supply from the grid in some cases turn out to be higher than the cost for owning generation as a part of a microgrid, it can be assumed that some consumers will prefer AEC to a more familiar and understandable solution technological connection or an increase in connected capacity.

Forecasted volume of Russian market for commercial and industrial microgrids is presented in Figure 1. By 2028, it will have reached 1.2 GW of installed capacity per year, or 175 billion rubles per year in monetary terms, depending on the scenario of the country's economy growth [7].Thus, the development of the industrial microgrid market in Russia within the framework of the AEC concept can provide an additional economic effect, including not only savings for consumers in the AEC themselves, but also system-wide effects for the UES and SDGs. The use of microgrids will significantly reduce an industrial enterprise's costs for power supply and increase the depreciation of fixed assets, since there will be no surges in the power grid. Reducing these costs will reduce the cost for industrial products, which will lead to an increase in profits, a reduction in costs for the same level of manufactured products and an opportunity to take a more competitive position in the market of manufactured products.

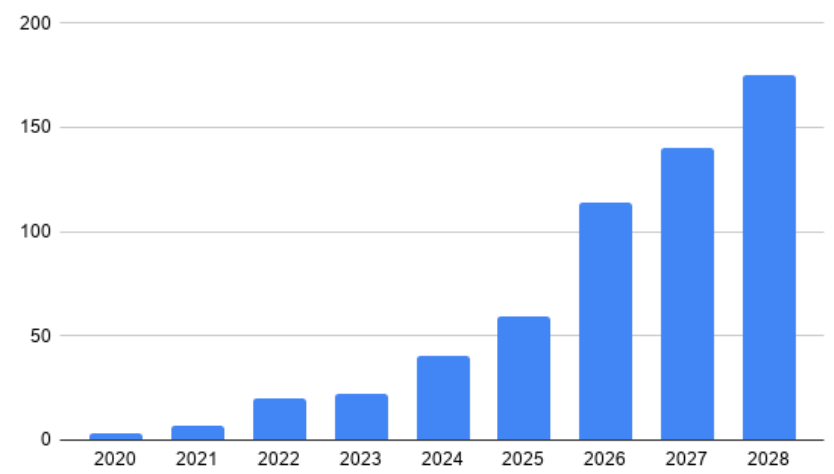

Fig. 1. Russian industrial microgrid market forecast (billion rubles / year)

This complex has the following advantages: redistribution of energy flows within its limits of responsibility, which makes it possible to reduce losses during the transmission of electrical energy, thereby reducing the main costs of transportation of electrical energy. AEC makes it possible to organize optimal operating modes of generating capacities, relying on the exact values of the power consumed by the consumer, thereby reducing the inertia of the power supply system, as well as reducing losses during the transmission of electricity. RES complexes can be combined into complex structural connections with each other, thereby allowing, depending on the type and type of consumer, to set one or another 
level of responsibility for his energy supply, which allows to ensure more reliable energy supply to consumers.

The key disadvantage of this complex is the use of renewable energy sources without using the distributed generation method in the system's generation system. A great dependence on a natural energy source (water, wind, sun, etc.) will be created and, therefore, this source will depend on the random behavior of the selected RES. The second drawback is the high cost of manufacturing converting equipment.

Consequently, this system is a complexly organized system that requires an integrated control system, from the amount of generated energy to the amount of electricity consumed.

\section{Economic efficiency of using AEC}

As an example, consider the production association Novosibirsk Tool-Making Plant with a power consumption of $25 \mathrm{MW}$ and an average annual electricity consumption of 7.96 million $\mathrm{kWh}$. The consumption profile on weekdays is shown in Figure 2, the electricity consumption at weekends was considered to be $25 \%$ lower than on weekdays. It should be clarified that the capacity of technological connection without reconstruction of the supply center is limited to $20 \mathrm{MW}$, and the cost of increasing the capacity of technological connection to the required $25 \mathrm{MW}$ is 80 million rubles.

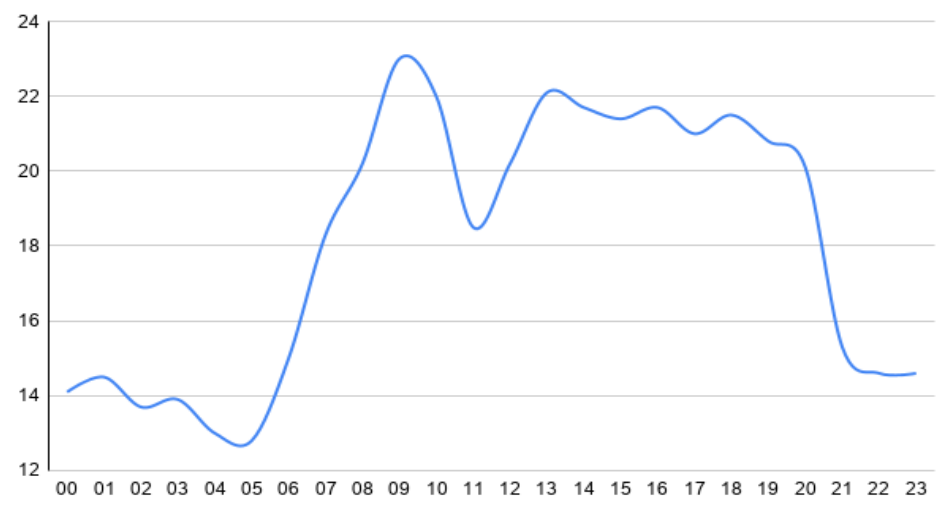

Fig. 2. PA NTMP Electricity consumption profile (average electricity consumption, MW)

As an alternative to increasing the connected capacity, the installation of own generation as a part of gas piston units with a total capacity of $20 \mathrm{MW}$ was considered. These units are used both to cover the deficit of connected capacity and to optimize the cost of electricity by reducing consumption from the grid and a corresponding reduction in payments for capacity and for transmission of electricity services [8].

Table 2 shows the main economic characteristics of such a microgrid creating project. The calculation of the levelized cost of electricity LCOE per kWh during the entire life of the power plant can be used, which equates the present value of revenue from generation and sale of electricity to the present value of costs for the power plant construction and operation.

$$
\operatorname{LCOE}=\frac{\text { TLCC }}{\sum_{n=1}^{N} Q_{n} /(1+d)^{n}}
$$

Optimization according to the minimum LCOE criterion leads to the option of using the own generation to cover $95.7 \%$ of industrial site's demand for electricity, while the 
utilization factor of the installed capacity of the GCU reaches $70.2 \%$. IRR of the project reaches $34.8 \%$.

Table 2. Economic characteristics of the microgrid project for PA NTMP

\begin{tabular}{|l|l|}
\hline Parameter & The resulting value, in million \$ \\
\hline Capital expenses for microgrid (CAPEX) & 20 \\
\hline Operating expenses per year & 2,82 \\
\hline including expenses for purchasing electricity & 0,467 \\
\hline
\end{tabular}

For a comparative assessment of economic efficiency, LCOE can be calculated in two options: electricity supply from the grid only with the purchase of electricity and capacity according to the current rules and prices and electricity supply using own energy sources and flexibility, combined with the purchase of the part of required electricity from the grid. Table 3 shows the simulation results, which indicate that the savings in consumption due to the microgrid will amount to 1.78 rubles per each $\mathrm{kWh}$ consumed.

Table 3. Comparison of power supply options economic characteristics

\begin{tabular}{|l|l|l|}
\hline Power supply option & $\begin{array}{l}\text { LCOE, \$ per } \\
\mathrm{kWt}\end{array}$ & $\begin{array}{l}\text { Economic impact } \\
\text { compared with the } \\
\text { basic option }\end{array}$ \\
\hline Basic. Grid power supply & 0,0799 & $31,9 \%$ \\
\hline Microgrid. Gas generation and grid power supply & 0,0544 & \\
\hline
\end{tabular}

\section{Conclusion}

In Russia, as elsewhere in the world, a significant factor influencing the increase in demand for AEC microgrids in the future, will be the development of economy sectors with increased sensitivity to the quality of electricity and power supply reliability, for example, data centers (data processing centers), digital enterprises using 3D printing technologies, composite materials, biopharmaceutical and other high-precision enterprises. In some cases, the cost for power supply from the external grid turns out to be higher than the cost for owning generation as a part of the AEC microgrid. The use of distributed generation in isolated industrial enterprises is economically justified: the payback period of distributed generation devices is much shorter than their service life. It can be assumed that in the future, some of the consumers creating demand for electricity and capacity will prefer AEC to technological connection to the UES.

In Russia, today and in the future, it is the sector of industrial consumers that can become the locomotive of the microgrid market, since, on the one hand, the problem of growth in electricity supply costs is most acute precisely for such consumers and they have a direct interest in using the possibilities of distributed generation. On the other hand, it is these consumers who are able to generate effective demand and invest their resources into microgrids creation and necessary technologies development.

\section{References}

1. United Nations, Sustainable Development Goals Report 2020, 2 (2020)

2. STC UES, Active energy complexes, 5 (2020)

3. Z. Paskevich, Meet AEC! (2020) 
4. V. Sidorovich, AEC is the first step towards industrial microgrids in Russia (2020)

5. Global Microgrid Deployment Insights, Analyst Insight: Microgrid Market Segment Winners and Losers (2021)

6. World Business Council for Sustainable Development, Microgrids for Commercial and Industrial Companies (2017)

7. STC UES, Active energy complexes, 10 (2020)

8. I. Ivanov, Proceedings - 2020 International Conference on Industrial Engineering, Applications and Manufacturing, ICIEAM, 9112062 (2020) 